\title{
Chapter 23 \\ Publishing in the Journal of Mathematics Teacher Education
}

\section{Despina Potari}

\begin{abstract}
This chapter has the aim of supporting early career researchers who want to publish a paper in the Journal of Mathematics Teacher Education (JMTE) by providing them with information about the scope of the journal, its impact on the field, the papers published, the reviewing process and the required quality. It ends by providing some advice on issues that an early career researcher needs to consider if he or she decides to submit a paper to JMTE.
\end{abstract}

Keywords Quality of research • Reviewing process · Journal of Mathematics Teacher Education

\subsection{Introduction}

JMTE is one of the mathematics education journals published by Springer. It was founded by Professor Tom Cooney in 1998 as a journal specializing in mathematics teacher education research and practice. Although the life of the journal is rather short, JMTE has been established among the top journals in mathematics education (Williams and Leatham 2017).

Cooney (1998), in his first editorial, considered JMTE as a professional setting for mathematics teacher educators to communicate their work both at the research and practice levels:

The establishment of the Journal of Mathematics Teacher Education (JMTE) provides us with a forum singularly devoted to our work in teacher education. Indeed, we now have more reason than ever to integrate our study of teacher education with our practice of teacher education. We have much to learn. (p. 1)

Theory-practice relations, diversity of ideas and perspectives, acknowledgment of the complexity of mathematics teaching and mathematics teacher education as

D. Potari $(\bowtie)$

National and Kapodistrian University of Athens, Athens, Greece

e-mail: dpotari@math.uoa.gr

(C) The Author(s) 2019

G. Kaiser and N. Presmeg (eds.), Compendium for Early Career

Researchers in Mathematics Education, ICME-13 Monographs,

https://doi.org/10.1007/978-3-030-15636-7_23 
well as theorization and critical analysis have been important goals of JMTE throughout its 20 years' journey.

I have contributed to JMTE since its establishment in different roles, including those of author, reviewer, member of the editorial board, associate editor, and as editor in chief, and so I have participated in this journey. In this chapter I provide some information about the journal and share some of my experiences, especially related to the reviewing process, which may be helpful to an early career researcher who has done research related to mathematics teachers and mathematics teacher education, and who wants to publish it in JMTE.

The chapter is structured in six sections, after the introduction 23.1. Section 23.2 concerns the scope of the journal. Section 23.3 provides information about the acceptance rate and the impact of JMTE in the international research community. Section 23.4 presents the results from a short survey of the content, theoretical perspectives and methodologies of the papers published in 2017. Section 23.5 discusses the process from the submission until the publication of a paper, focusing mainly on the procedure itself. Section 23.6 discusses the reviewing and decision making process, focusing mainly on issues of quality. Section 23.7 concludes with some guidelines for early career researchers focusing on main issues to consider when they prepare a manuscript for JMTE.

\subsection{The Scope of the Journal}

In the homepage of the journal the scope of the journal is presented, which I cite below:

The Journal of Mathematics Teacher Education (JMTE) is devoted to research into the education of mathematics teachers and development of teaching that promotes students' successful learning of mathematics. JMTE focuses on all stages of professional development of mathematics teachers and teacher educators and serves as a forum for considering institutional, societal and cultural influences that impact on teachers' learning, and ultimately that of their students. Critical analyses of particular programmes, development initiatives, technology, assessment, teaching diverse populations and policy matters, as these topics relate to the main focuses of the journal, are welcome. (JMTE homepage)

This scope was determined by the founding editor and has been clarified by subsequent editors and editorial teams. In her editorial, Jaworski (2005) addressed the close links among mathematics teacher education, mathematics teaching and students learning that studies in JMTE have reported:

It allows the linking of theory in the learning of mathematics to the learning of teachers of mathematics, and considerations of how teachers learn related to the learning of their pupils. Increasingly it allows us to address the learning of teacher educators and its relation to the learning of teachers. (p. 1).

Although students' learning is an ultimate goal of mathematics teacher education and mathematics teaching, a study on students' learning per se is not in the scope of JMTE. 
Education of mathematics teachers includes both initial teacher education and also professional development initiatives. However, its scope goes beyond programs, tasks, or approaches used for the education of prospective and practicing mathematics teachers. Chapman (2011), in her first editorial as editor in chief, pointed out that it also involves the study of the mathematics teacher focusing on her beliefs, knowledge, identity and teaching practice. Nevertheless, the ways that the emphasis on the mathematics teacher informs mathematics teaching and in particular mathematics teacher education needs to be considered by the authors of JMTE. A current emphasis on mathematics teacher educators in the field of mathematics education is also reflected in the published papers in JMTE and in the current special issue published in issue 5 of volume 21 . The relation between mathematics teachers, mathematics teacher educators, mathematics teaching and mathematics teacher education is very complex and cannot be studied through cause-effect approaches. JMTE acknowledges the importance of addressing this relation by considering contextual dimensions that play an important role in understanding this complexity.

Diversity is also promoted in relation to theoretical perspectives, methods and content areas. A sense of this diversity is provided in Sect. 23.4 through the analysis of the papers published in 2017. Submitted manuscripts need to have a clear focus on mathematics teacher education and not to teacher education in general. Also, the authors need to be able to justify the importance of mathematics in their study.

Summarizing, a paper to be published in JMTE should focus on approaches in mathematics teacher education (initial and professional development), on the main participants in mathematics teacher education (mathematics teachers and mathematics teacher educators) or on classroom teaching with the mathematics teacher being the centre of attention. Large-scale or small-scale studies, studies adopting different theoretical perspectives (ranging from cognitive to socio-cultural and socio-political) and methods (quantitative and qualitative) are welcome in the journal.

\subsection{Acceptance Rate and Impact}

Six issues per year are published in JMTE (before 2005 four issues were published) with an average of 24 papers published per year. Up to today (September 2018) 2035 manuscripts have been submitted to the journal and 395 research papers have been accepted and published (in regular issues and in online first) while 9 papers have been published in the section on mathematics teachers around the world, and 15 in the section on reader commentary - mainly book reviews. The acceptance rate has varied through the years but on the average is about $20 \%$.

The impact that a journal has in the field is measured by the number of the citations of papers published in this journal. The impact factor (IF) gives an indication of the quality of a journal in relation to its citations. However, JMTE is not 
indexed in the Social Science Citation Index (SSCI) data base so IF is not available. Williams and Leatham (2017) found that JMTE is fifth in the order of the ten most cited journals in mathematics education, and through a survey based on experts' opinions they ranked it as fifth in the order of high quality journals of mathematics education. In the site of JMTE some journal metrics can be found. In 2017, 89,816 downloads of papers were counted; different impact factors have been calculated in different ways (the impact factor by CiteScore 2016 is 1.14, by SNIP-2016 is 1,317, by SJR-2016 is 1,041 and the h5 Index-22016 is 21); and in 2017, 80\% of the authors said that they would be likely to publish again in this journal.

\subsection{Papers Published in JMTE}

Cooney (2000) raised the question about the character of JMTE in the year 2010, and in future years 2020 or even 2050 . He foresaw possible changes in the research on and practice of mathematics teacher education, due to the extended use of technology as well as the differences of current reforms in relation to ones targeted in the nineties. Nevertheless, he expected that mathematics teachers' learning and mathematics teacher educators' struggles would be central topics in JMTE. To do a systematic survey in order to explore the development of the journal is beyond the scope of this chapter, but I discuss below the papers published in JMTE in 2017 in terms of their focus, the participants, the research methodology and the adopted theoretical perspectives. This analysis may offer insights to young researchers on the diversity of the mathematics teacher education research reported in this journal. A classification of the papers is presented in the systemic network in Fig. 23.1. Teacher resources such as beliefs, knowledge, and identity, teacher education programs and their impact on prospective teacher development, teacher noticing of students' mathematical thinking are research areas indicating that JMTE fullifils the expectations of its founder as it focuses on the mathematics teacher and on the struggles of mathematics teacher educators to support (prospective and practicing) teachers' learning. Papers also focus on classroom teaching and its development as well as on mathematics teacher collaboration. The role of technology in mathematics teacher education research is mainly seen through the use of video in promoting teacher noticing or through the use of dynamic geometry software (DGS) in classroom teaching.

Concerning the participants, most of the studies focus on prospective primary school teachers while teacher educators have become the focus of attention in some studies. In the papers published in 2017 we see also the multiplicity of theoretical perspectives and methodological approaches that the scope of the journal underlines. However, cognitive perspectives and qualitative research methods are most commonly adopted. Although this short survey does not give an overall picture of the papers published in JMTE, to some extent they fit in with the current research on mathematics teacher education research reported in other review studies (Strutchens et al. 2016). 


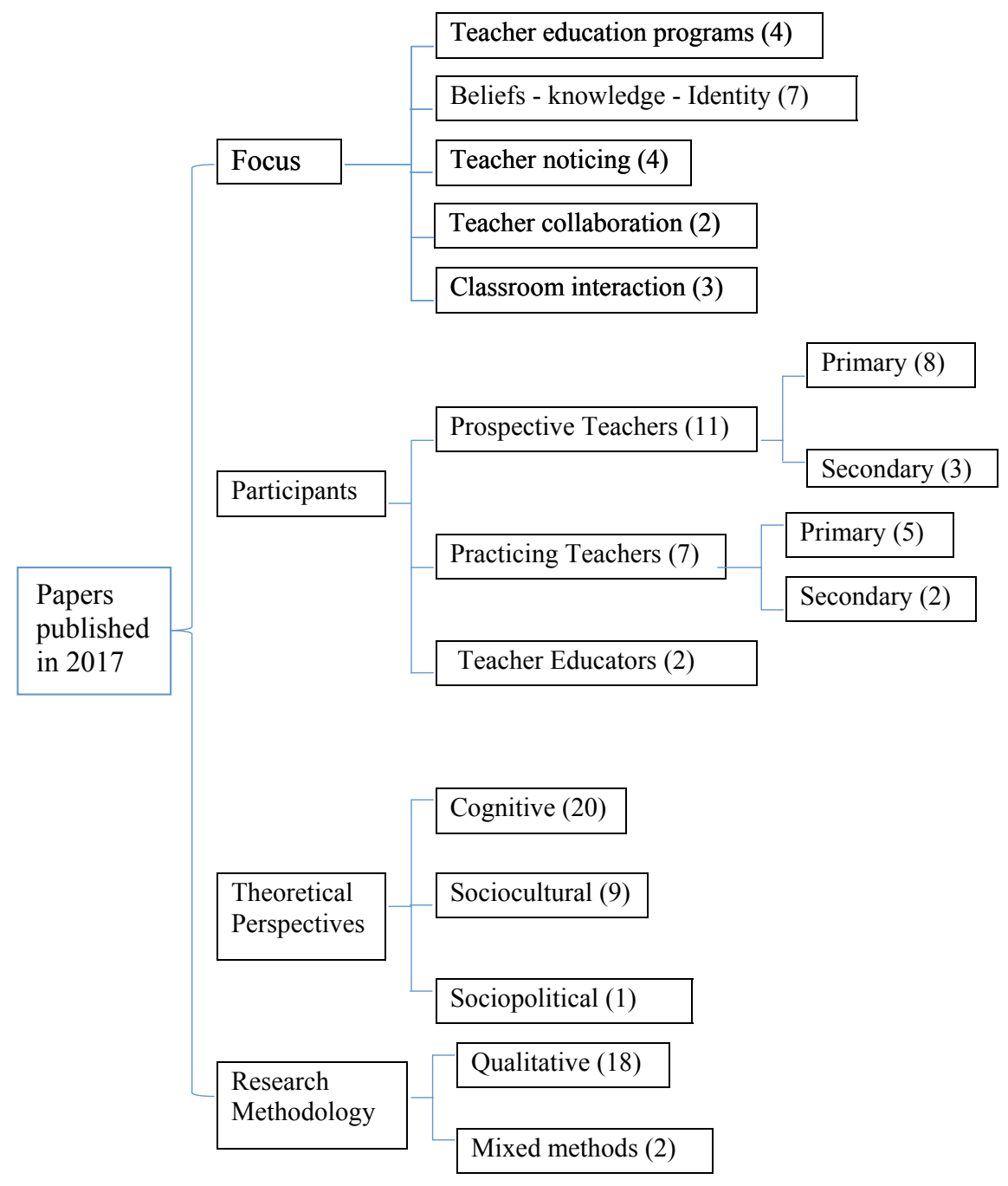

Fig. 23.1 Papers published in JMTE in 2017

\subsection{From Submission to Publication}

\subsubsection{Submission of a Manuscript}

Manuscripts submitted to JMTE can fall into one of three sections: research papers, mathematics teacher education around the world, and reader commentary. In the manuscript submission, authors should state clearly the section for which their paper will be considered. 
Research papers should reflect the main scope of the journal discussed in Sect. 23.2 and should address the international audience. These are rather long papers (up to 10,000 words) that can report studies based on empirical data or can be theoretical or methodological ones. In these papers the originality and contribution to knowledge needs to be well justified.

Manuscripts submitted for the section mathematics teacher education around the world are shorter than the research papers (up to 5000 words) and report more than just a research study taking place at a specific national context. They need to report programmes and/or issues of national significance (e.g., a large scale professional development program, the implementation of a national curriculum in a country, mathematics teacher education practices around the country) that could be of wider interest to the international research community.

Manuscripts submitted for the section of reader commentary are short contributions (up to 3000 words) that can offer a response to a paper published in JMTE, or develop a theoretical idea. Book reviews related to mathematics teacher education can also be published in the journal.

Any submission in one of these three sections needs to meet the following ethics criteria, ensuring the following: that the paper has not been published before or been under consideration for publication somewhere else; that all the co-authors have approved the publication; and that permission from the copyright owner has been obtained for figures, tables or text passages that have been published elsewhere. Following the ethics in relation to conducting the research is increasingly an issue for the journal, which the editorial team, the editorial board, and the reviewers take into account.

The journal publishes also special issues addressing a particular research area. In this case, researchers (acting as guest editors) can make a proposal for a special issue to the chief editor. The proposal needs to justify the importance of this area of research and provide solid arguments why this will be of interest to the JMTE audience. When the proposal is accepted by the editor, the call for the special issue appears in the homepage of the journal and manuscripts are submitted through the editorial manager.

Before submitting a manuscript, the author needs to read carefully the instructions for authors provided in the homepage of JMTE, and to follow them while preparing the manuscript. The submission is made online through the editorial manager of JMTE. The author selects on the homepage of the journal the hyperlink 'Submit online' and follows the instructions on how and what materials need to be uploaded. The author can track the status of his/her submission through the system.

\subsubsection{The Reviewing Process}

When the manuscript is submitted, the editor in chief is informed through the system about the new submission. The editor reads the paper and checks if it is in the scope of the journal and then either sends it to reviewers or assigns it to one 
of the associate editors who will manage the reviewing process. Manuscripts that are not in the scope of the journal are rejected by the editors without sending them out for review. Reviewers can be members of the editorial board or researchers around the word that are registered in the editorial manager. The editor can also add a new reviewer into the system. Searching for reviewers can be done through the editorial manager by using specific keywords (e.g., name, country, university, research area). Three reviewers are usually invited by the editors on the basis of their expertise in the area of research reported in the paper. Sometimes, the reviewer does not accept the invitation so a new reviewer is invited. This cycle may be repeated several times. The reviewers are given 35 days to submit their reviews. On the basis of the three reviews and of her own reading, the editor decides if the paper will be (a) accepted for publication without further changes, (b) accepted for publication if minor revisions will be undertaken by the author, (c) reconsidered for sending for a second round of reviews after major revisions, or (d) rejected. The time needed for the author to get an initial response for his or her submission is approximately four months. While in the case of minor revisions the revised version is reviewed by the editor, the case of major revisions requires a new reviewing cycle. Usually, some of the reviewers used in the first round are invited for the second round and some new ones are added. Nevertheless, there are a few cases in which the reviewers who accept the invitation had not reviewed the paper before. However, the reviews from the first round and the decision letter of the editor, together with the initial and revised submissions, are made available to the reviewers of the second round.

Usually, after this cycle of review the paper is either accepted (with or without minor revisions) or rejected, while there are a few exceptional cases where a new reviewing cycle can start. If the manuscript requires minor revisions, the revised paper (in most cases) is reviewed only by the editor and no other reviewers are invited. To get acceptance after two reviewing cycles takes more than one year.

\subsubsection{Publication}

When the paper is accepted by the editor it goes to the publishing office. The authors receive the proofs of their papers, which they need to check. In this process they mainly have to accept some editorial changes that have been made in the paper, provide some clarifications that the publisher asks for, or make some final minor changes (mainly typographical) in the text. The time from the acceptance to publishing is rather short-it takes about 10 days for the paper to be published online first. The time needed for the paper to be published in a regular issue depends on the number of papers accepted in the journal at this period of time. 


\subsection{Deciding on the Quality of a Submission}

The quality of a study and of a paper has always been an issue of concern in the research community. Quality is usually discussed in doctoral programs, mainly in the context of courses on research methodology. Public discussion on this issue takes place in journal papers and book chapters. Kilpatrick (1993) argued for quality criteria such as relevance, validity, objectivity, originality, rigour and precision, predictability, reproducibility and relatedness. These criteria were elaborated by other researchers in their attempts to communicate the nature of research in mathematics education (Schoenfeld 2000). However, these criteria have been challenged as they have been considered rather rigid. For example, Simon (2004) considered quality in relation to the strength of arguments of the researcher.

Quality criteria in JMTE are not defined explicitly in the homepage, but actually quality is evaluated through the expertise of the members of the editorial board, the reviewers and the editors. Quality improvement of a submitted manuscript is made through the interaction among the author, the reviewers and the editor. A professional learning community is established with a goal of reviewing and developing further the quality of the paper, where the author is a member of this community. The author's (professional?) learning takes place through the revision process while attempting to recognize/appreciate the reviewers' different perspectives and address their comments. The reviewers and the editor are learning in the process of reviewing the paper but also from reading the other reviewers' reviews, which become available to all reviewers who have access in the editorial manager. Although there are cases in which reviewers may have different opinions about the quality of a manuscript, in most cases there is an agreement about the strengths and the weaknesses of the submission.

In Table 23.1, through some illustrative examples, I present issues of quality raised often by reviewers. The examples have been modified or in some cases have been developed by me for ethical reasons of anonymity.

The study's contribution to knowledge is a main issue that reviewers address. The authors need to make explicit what their study adds to what we already know on the research area that their study addresses. For example, the contribution could be related to important empirical findings or to new methodological and theoretical perspectives to study a phenomenon. The clarity of the article is another issue that is very often addressed by the reviewers. Clarity may be related to the following: the focus and the research questions; the coherence between research questions, theoretical framework, design of the study and findings; the justification of claims; and the use of language. Comments about theoretical perspectives are mainly related to the definitions of theoretical constructs used in the study and to the way that these perspectives are operationalized in data analysis and presentation of results. Methodological issues addressed by the reviewers often refer to the need for more contextual information and for detailed description of the data analysis process. Addressing the quality of the submission is often challenging even for experienced reviewers. There are cases where a manuscript may have clear research 
Table 23.1 Quality issues often addressed by reviewers

\begin{tabular}{|c|c|}
\hline Issues of quality & Examples \\
\hline $\begin{array}{l}\text { Contribution to } \\
\text { knowledge }\end{array}$ & $\begin{array}{l}\text { "It is not clear what we might generalize from this study. You discuss } \\
\text { about a sequence of tasks but what are the key features of the task } \\
\text { sequence that may develop new knowledge to the field about how to } \\
\text { support prospective teachers?" }\end{array}$ \\
\hline $\begin{array}{l}\text { Clarity of research } \\
\text { questions }\end{array}$ & $\begin{array}{l}\text { "I left the section wondering what exactly is your purpose for the } \\
\text { study. I wanted a clearly stated research goal" }\end{array}$ \\
\hline Theoretical framing & $\begin{array}{l}\text { "The theoretical grounding is conducted in a very shallow way. What } \\
\text { do these particularly cited authors actually say, and how does the } \\
\text { theory referred to implement and ground the reported research?" } \\
\text { "The concept of identity is a fragile and elusive concept that needs to } \\
\text { be clearly defined and theoretically elaborated and then to be used in a } \\
\text { consistent manner" } \\
\text { "There are important constructs not defined, used in a sort of naive } \\
\text { meaning: for example, authors discuss attitudes' change in the result } \\
\text { section but they don't give any explicit definition of the construct" }\end{array}$ \\
\hline $\begin{array}{l}\text { The context of the } \\
\text { study }\end{array}$ & $\begin{array}{l}\text { "Practices differ so much across the world that for an international } \\
\text { journal the context seems important" }\end{array}$ \\
\hline $\begin{array}{l}\text { The justification of } \\
\text { claims }\end{array}$ & "Your claims do not seem to be grounded in empirical evidence" \\
\hline The analytical process & $\begin{array}{l}\text { "More care is needed in making connections between the methods and } \\
\text { the findings. But more fundamentally, although this looks like an } \\
\text { interesting exercise in quantitative data analysis, I am seriously } \\
\text { unconvinced that the findings could be generalised beyond the } \\
\text { surprisingly small set of participants in this study" } \\
\text { "I think that the article would benefit from a more coherent and specific } \\
\text { explanation of how exactly the analysis was carried out at this phase" }\end{array}$ \\
\hline $\begin{array}{l}\text { The discussion of the } \\
\text { findings }\end{array}$ & $\begin{array}{l}\text { "The results are too descriptive and do not give a better insight into } \\
\text { teachers' practices in problem solving. That is the reason the } \\
\text { conclusions of the study do not contribute any further to the } \\
\text { well-known importance of teachers' mastery in problem solving" } \\
\text { "There are too many new ideas in the conclusions that are not } \\
\text { addressed in the results" }\end{array}$ \\
\hline $\begin{array}{l}\text { Coherence of the } \\
\text { article }\end{array}$ & $\begin{array}{l}\text { "There is not a clear focus in the article since in different parts of the } \\
\text { manuscript the reader could spot different research focus statements" } \\
\text { "Make sure that the research question and conclusion align. It seems } \\
\text { that additional questions were addressed that are not included in the } \\
\text { current question" }\end{array}$ \\
\hline
\end{tabular}

goals, explicit theoretical framework, appropriate methodology, well-structured results, but a weak contribution to the field. The question 'so what?' cannot be easily answered in the research community. Niss (2018) invites researchers to reconsider issues of quality beyond the "ideal-typical mathematics education research article" that meets a number of quality criteria:

... more than ever we must analyse and discuss quality, but in the same way as we should not endorse only one understanding and version of democracy, like the one found in, say, Switzerland, in the USA, or in Denmark, we should not allow too narrow and rigid paradigms to jeopardise our discussions or our field of research. (p. 48) 
In summary, deciding on the quality of a submission is related not only to the policy of this journal. Rather, it is a decision the reviewers and editors take in the process of participating in the mathematics education research community. Searching for the quality constitutes a professional learning experience for authors, reviewers and editors, characterized by considering perspectives outside their own and inquiring into their research practice collectively.

\subsection{Advice to Early Career Researchers and Concluding Remarks}

In this section, I attempt to give some advice that may seem helpful to an early career researcher who would like to submit a manuscript to JMTE, on the basis of my experience with the process of publishing a paper in JMTE from different positions (author, reviewer, editor).

- The manuscript needs to fit in with the scope of the journal, to be suitable for one of the three sections (research article, mathematics education around the world, commentary article) and to comply with the word limits.

- The high quality of the paper is the main requirement for a paper to be published in JMTE. This criterion means that it should have interesting and important research questions, clarity and coherence, explicit theoretical and methodological framework, solid empirical evidence of the claims, and make a contribution to the field.

- If the submission is rejected because it is not in the scope of JMTE, then the authors need to select carefully another journal that is appropriate in relation to the content of the manuscript and its perspective.

- In case the rejection relates to the quality of the submission, then the authors need to read carefully the comments of the reviewers and the editor and see if the suggested changes can be made for a future resubmission to JMTE or to another journal. Revise and resubmit is not a possible decision up to now for $J M T E$, so the editor may suggest informally to the authors that they rewrite most parts of the article and submit it again to JMTE. Otherwise, the editor would suggest that the authors send the revised article to another journal.

- In case of major revisions, the authors need to think carefully in which directions the revision will go. The decision letter and the suggestions of the editor would help the authors to recognize these directions and through reviewers' comments to decide on how to deal with them. It is important for the author to distinguish the significant from the minor changes that need to be undertaken.

- The first reaction of the authors to the editor's and reviewers' comments is usually emotional. The authors have done much work in conducting the study and reporting on it. Thus, it is quite common to feel frustrated when weaknesses of their work are addressed. Overcoming these feelings is important for starting the revision. Considering the perspectives of others is the first step for improving the article. 
Revising the article is not only responding to the editor's and reviewers' comments. Reflecting on the received feedback, the authors develop better understanding of their study, identifying strengths and weaknesses. On this basis, the authors take decisions on how they will structure the revision of the article.

The authors also need to pay attention to language and editing issues. Communicating their work is also important. For example, following the APA style consistently throughout the paper, avoiding typographical mistakes, getting help with the language from a native English person, will improve the clarity of the article and make easier the communication of the authors' ideas. In addition to APA guidelines, JMTE has also some specific style aspects in relation to expressions that need to be used. For example, the use of "teacher education" instead of "teacher training", "prospective teachers" instead of "pre-service teachers", "practicing teachers" instead of "in-service teachers" are some of the main expressions.

Regardless of the outcome of the reviewing process, the feedback that the authors get helps them to develop their research further, beyond the specific submission. Through the whole process the authors communicate with other colleagues who have worked on similar research areas and they open their work to the international research community.

Overall, JMTE is a high quality mathematics education journal, with a strong impact on the field of mathematics education and in particular on the area of mathematics teacher education. It accepts different types of papers with a diversity of research foci, theoretical and methodological perspectives. The editorial team, the board and the body of reviewers registered in the editorial manager have long experience in the area of mathematics teacher education and so they can provide rich feedback to authors whose studies fall in this area. Therefore, JMTE is a journal appropriate for an early career researcher whose research focuses on mathematics teacher education, on mathematics teacher resources, or on mathematics teaching with a particular focus on the mathematics teacher.

\section{References}

Chapman, O. (2011). The field of research in mathematics teacher education. Journal of Mathematics Teacher Education, 14, 247-249.

Cooney, T. J. (1998). Hospitality and homage. Journal of Mathematics Teacher Education, 1, 1-2.

Cooney, T. J. (2000). The millennium and mathematics teacher education. Journal of Mathematics Teacher Education, 3, 1-20.

Jaworski, B. (2005). New beginnings and recurring themes. Journal of Mathematics Teacher Education, 8, 1-3.

Kilpatrick, J. (1993). Beyond face value: Assessing research in mathematics education. In G. Nissen \& M. Blomboj (Eds.), Criteria for scientific quality and relevance in the didactics of mathematics (pp. 15-34). Roskilde: Danish Research Council for the Humanities.

Niss, M. (2018). The very multi-faceted nature of mathematics education research. In E. Bergvist, M. Osterholm, C. Granberg \& L. Sumpter (Eds.). Proceedings of the 42nd Conference of the International Group for the Psychology of Mathematics Education (Vol. 1, pp. 35-50). Umeå, Sweden: PME. 
Simon, M. (2004). Raising issues of quality in mathematics education research. Journal for Research in Mathematics Education, 35, 157-163.

Schoenfeld, A. H. (2000). Purposes and methods of research in mathematics education (pp. 641649). June/July: Notices of the AMS.

Strutchens, M., Huang, R., Losano, L., Potari, D., Ponte, J. P. D., Cyrino, M. C. D. C. T., et al. (2016). The mathematics education of prospective secondary teachers around the world. Cham, Switzerland: Springer Open.

Williams, S. R., \& Leatham, K. R. (2017). Journal quality in mathematics education. Journal for Research in Mathematics Education, 48, 369-396.

Open Access This chapter is licensed under the terms of the Creative Commons Attribution 4.0 International License (http://creativecommons.org/licenses/by/4.0/), which permits use, sharing, adaptation, distribution and reproduction in any medium or format, as long as you give appropriate credit to the original author(s) and the source, provide a link to the Creative Commons license and indicate if changes were made.

The images or other third party material in this chapter are included in the chapter's Creative Commons license, unless indicated otherwise in a credit line to the material. If material is not included in the chapter's Creative Commons license and your intended use is not permitted by statutory regulation or exceeds the permitted use, you will need to obtain permission directly from the copyright holder.

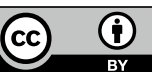

